\title{
PERAN KEPUASAN KONSUMEN MEMEDIASI PENGARUH MARKETING MIX TERHADAP NIAT BELI ULANG DEWATA KAOS DI DENPASAR
}

\author{
Putu Susmithasen Sari Dewi Maharani ${ }^{1}$ \\ I Made Jatra ${ }^{2}$
}

${ }^{1}$ Fakultas Ekonomi dan Bisnis Universitas Udayana, Bali, Indonesia email: sensarisusmitha@gmail.com

\begin{abstract}
ABSTRAK
Trend fashion yang terus berkembang silih berganti, membuat perusahaan perlu menerapkan strategi pemasarakn yang optimal. Strategi marketing mix merupakan alat dasar berupa seperangkat variabel terkontrol yang digunakan oleh perusahaan untuk mencapai pasar sasaran. Suatu kepuasan konsumen sangat berpengaruh terhadap penjualan perusahaan. Setiap perusahaan dituntut untuk mengerti dan memahami strategi pemasaran yang tepat agar konsumen merasa puas dan terjadi niat pembelian ulang sehingga dapat meningkatkan penjualan pada perusahaan. Penelitian ini bertujuan untuk menjelaskan peran kepuasan konsumen dalam memediasi pengaruh marketing mix terhadap niat beli ulang.Penelitian ini menggunakan data primer yang didapat dengan menyebar kuisioner, secara offline (secara langsung) dan online (google form) kepada responden yaitu konsumen dewata kaos yang berdomisili di kota Denpasar dengan sampel sebanyak 110 orang, menggunakan metode purposive sampling. Teknik analisis yang digunakan adalah Uji Asumsi Klasik, Analisis jalur (Path Analysis) dan Uji Sobel. Hasil penelitian menunjukan kepuasan konsumen mampu memediasi pengaruh marketing mix terhadap niat beli ulang pada produk Dewata Kaos di Denpasar.
\end{abstract}

Kata kunci: Marketing mix, kepuasan konsumen, niat beli ulang

\begin{abstract}
Trends Fashion that continue to evolve and turn, make companies need to implement an optimal marketing strategy. The marketing mix strategy is a basic tool in the form of a set of controlled variables used by companies to reach target markets. A customer satisfaction is very influential on company sales. Every company is required to understand and understand the right marketing strategy so that consumers feel satisfied and there is a repurchase intention so that it can increase sales to the company. This study aims to explain the role of consumer satisfaction in mediating the effect of the marketing mix on repurchase intention. This study uses primary data obtained by distributing questionnaires, offline (in person) and online (google form) to respondents Dewata Kaos consumers who live in Denpasar city with asample of 110 people, using a purposive sampling method. The analysis technique used is the Classical Assumption Test, Path Analysis and Sobel Test. The results showed that consumer satisfaction was able to mediate the effect of the marketing mix on repurchase intention of Dewata Kaos products in Denpasar.

Keywords: Marketing mix, customer satisfaction, repurchase intention
\end{abstract}




\section{PENDAHULUAN}

Trend Fashion yang terus berkembang dan silih berganti, menjadikan masyarakat melihat hal tesebut sebagai peluang bisnis sekaligus dapat membantu para individu memenuhi kebutuhan sandang. Melihat besarnya peluang bisnis di bidang industri pakaian, menjadikan pasar yang potensial untuk usaha konfeksi di Indonesia. Dampaknya, timbul banyak usaha rumahan hingga Usaha Kecil Menengah (UKM) yang bergerak pada usaha konfeksi pakaian. Usaha konfeksi yang dapat bertahan, karena memiliki suatu ciri khas dalam proses produksi dan hasil produksi. Mampu bersaing secara kompetitif, memilik kekuatan dan keunggulan agar mempunyai daya saing dan pembeda dengan yang lainnya.

Dewata kaos merupakan salah satu konfeksi di Bali, berdiri sejak 1997 diawali sebagai industri rumahan. Persaingan konfeksi saat ini sangat kompetitif, dengan kemajuan teknologi serta berbagai inovasi produk pada fashion. Dewata Kaos, dapat tetap konsisten dalam persaingan dengan berbagai inovasi perkembangan fashion sehingga dapat bertahan sampai saat ini. Cara perusahaan untuk dapat terus bersaing adalah dengan menerapkan strategi marketing mix (bauran pemasaran) yang konsisten. Membuat konsumen merasa puas untuk membeli kembali produk yang sama di waktu yang akan datang atau disebut juga dengan menciptakan niat pembelian ulang. Fenomena tersebut membuat peneliti ingin mengetahui strategi yang di terapkan oleh Dewata Kaos. Cara perusahaan untuk dapat terus bersaing adalah dengan menerapkan strategi marketing mix (bauran pemasaran) yang konsisten.

Marketing Mix yaitu seperangkat variabel terkontrol yang digunakan oleh perusahaan untuk mencapai pasar sasar. Dasar alat pemasaran dalam Marketing Mix ialah 4P product, price, place, promotion (Kusuma \& Suryani, 2017). Produk (product) merupakan suatu barang atau jasa yang akan diterima seorang konsumen ketika mengeluarkan sejumlah uang. Harga (price) adalah jumlah uang yang dibutuhkan untuk mendapatkan suatu barang beserta pelayanannya. Perusahaan dapat menentukan harga dari produk tersebut sesuai dengan nilai yang ditawarkan. Distribusi (place) merupakan suatu aktifitas atau fungsi dalam memindahkan produk kepada hak pemiliknya. Promosi (promotion) merupakan salah satu strategi bauran pemasaran dalam mengkomunikasikan informasi produk atau jasa dari yang dijual, dari pihak penjual kepada pembeli.

Kepuasan konsumen sangat berpengaruh terhadap penjualan perusahaan, setiap perusahaan dituntut untuk selalu mengerti dan memahami strategi pemasaran yang tepat agar konsumen merasa puas dan terjadi pembelian ulang sehingga dapat meningkatkan penjualan pada perusahaan. Niat pembelian ulang merupakan proses dimana keputusan yang dilakukan oleh konsumen setelah melakukan pembelian atas produk yang ditawarkan atau dibutuhkan oleh konsumen tersebut. Niat pembelian ulang dapat dicapai dengan membangun serta mengelola suatu hubungan yang baik dengan terus memberikan nilai dan meningkatkan kepuasan pelanggan (Farida et al., 2016). Konsumen yang mendapatkan produk yang sesuai harapan serta keinginan tentu akan menjadi puas terhadap produk tersebut, sehingga bauran pemasaran berperan besar dalam meningkatkan kepuasan pelanggan (Tejantara et $a l ., 2018)$ Indikator kepuasan yang dapat digunakan sebagai acuan yaitu kepuasan secara keseluruhan (Supriyanto, 2013). 
Terdapat research gap pada penelitian sebelumnya oleh (Dimyati \& Mohamad Dimyati, 2018) menyatakan beberapa elemen bauran pemasaran tidak berpengaruh signifikan terhadap kepuasan konsumen yaitu price, place dan promotion, sedangkan hanya product yang berpengaruh signifikan terhadap kepuasan konsumen, sehingga hal tersebut yang harus menjadi perhatian perusahaan dalam mencapai kepuasan konsumen. Pelitian dilakukan oleh (Ferrand et al., 2010) menemukan hasil bahwa kepuasan konsumen tidak memiliki pengaruh yang signifikan terhadap niat pembelian ulang. Hal tesebut di dukung dalam hasil penelitian sebelumnya yang dilakukan oleh. Hal tersebut menyebabkan perlunya penelitian ulang kembali.

(Kusuma \& Suryani, 2017) pada penelitian sebelumnya menunjukan hasil marketing mix berpengaruh positif dan signifikan terhadap niat beli ulang. Hasil ini menunjukkan bahwa semakin baik pengelolaan marketing mix, maka konsumen cenderung untuk melakukan pembelian kembali. Senada dengan penelitian yang pernah dilakukan (Chayana et al., 2014) bahwa bauran pemasaran berpengaruh positif dan signifikan terhadap niat beli ulang produk balon yang ditawarkan. (Palma \& Andjarwati, 2016) juga menyatakan bahwa komponen bauran pemasaran berpengaruh signifikan terhadap niat beli ulang konsumen. Berdasarkan teori dan uraian tersebut, maka dapat disimpulkan hipotesis sebagai berikut:

$\mathrm{H}_{1}$ : Marketing Mix berpengaruh positif dan signifikan terhadap Niat Beli Ulang.

Penelitian terdahulu yang dilakukan oleh (Othman et al., 2020) menyatakan terdapat pengaruh positif dan signifikan pengaruh bauran pemasaran terhadap kepuasan konsumen. Hal tersebut di dukung oleh penelitian terdahulu yang dilakukan (Kadhim et al., 2016) menyatakan terdapat pengaruh positif dan signifikan pengaruh bauran pemasaran terhadap kepuasan konsumen.. (Wahyudi \& Prawatya, 2012) mengemukakan bahwa variabel bauran pemasaran berpengaruh positif terhadap kepuasan konsumen. Berdasarkan kajian empiris tersebut, maka dapat disimpulkan hipotesis sebagai berikut:

$\mathrm{H}_{2}$ : Marketing Mix berpengaruh positif dan signifikan terhadap Kepuasan konsumen

(Palma \& Andjarwati, 2016) dalam penelitian terdahulu memperlihatkan kepuasan konsumen dirasakan setelah mengkonsumsi atau menggunakan produk, sehingga dapat ditentukan tentang niat pembelian ulang terhadap produk atau jasa tersebut. Penelitian terdahulu oleh (Resti, Devi; Soesanto, 2016) dan (Nathadewi \& Sukawati, 2019) menemukan bahwa kepuasan pelanggan berpengaruh positif dan signifikan terhadap niat beli ulang. Berdasarkan kajian empiris tersebut, maka dapat disimpulkan hipotesis sebagai berikut:

$\mathrm{H}_{3}$ : Kepuasan Konsumen berpengaruh positif dan signifikan terhadap Niat Beli Ulang.

(Taali, 2018), (Tejantara et al., 2018) pada penelitian sebelumnya memeperoleh hasil penelitian, dimana variabel kepuasan konsumen memberikan pengaruh dalam elemen marketing mix terhadap niat beli ulang secara signifikan. Penelitian oleh (Kusuma \& Suryani, 2017) memperlihatkan peran kepuasan konsumen memediasi marketing mix terhadap niat beli ulang berpengaruh positif dan sginifikan. Berdasarkan teori dan uraian tersebut, maka dapat disimpulkan hipotesis sebagai berikut: 
$\mathrm{H}_{4}$ : Peran Kepuasan Konsumen Memediasi Marketing Mix Terhadap Niat Beli Ulang.

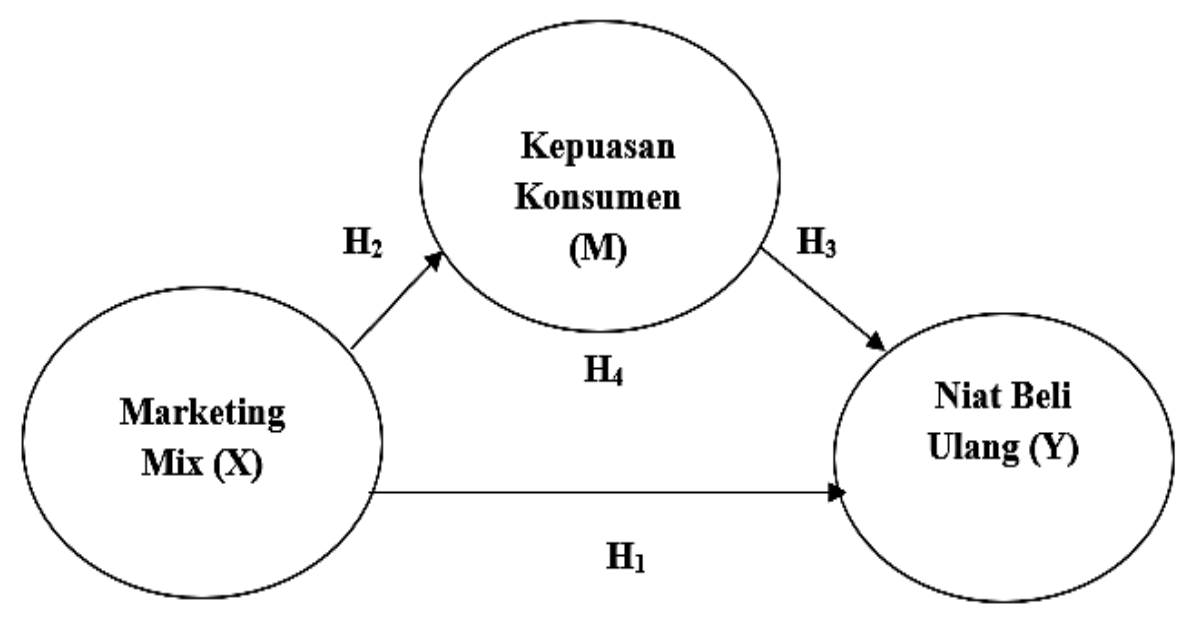

Gambar 1 .Kerangka Konseptual Penelitian

Sumber : (Kusuma \& Suryani, 2017)

\section{METODE PENELITIAN}

Metode penelitian merpakan metode asosiatif yang bersifat kausal (sebab akibat) untuk mengetahui pengaruh variabel bauran pemasaran (marketing mix) terhadap kepuasan konsumen dan dampaknya pada niat beli ulang produk. Menggunakan pendekatan Indikator - indikator setiap variabel mengacu pada beberapa sumber penelitian sebelumnya yang telah dimodifikasi menyesuaikan subjek penelitian ini Penelitian ini dilakukan di Kota Denpasar yaitu pada Konfeksi Dewata Kaos. Obyek penelitian ini adalah Kepuasan Konsumen, Marketing Mix dan Niat Beli Ulang Konsumen Dewata Kaos di Kota Denpasar. Kota Denpasar dipilih karena dekat dengan konsumen Dewata Kaos yang memiliki selera fashion bervariasi. Produk Dewata Kaos sangat bervariasi tergantung pada selera konsumen jika memesan secara custom order. Variabel yang diteliti ialah variabel independent yaitu marketing mix atau bauran pemasaran (X), Variabel mediasi yaitu Kepuasan Konsumen (M) dan Variabel dependen yaitu Niat Beli Ulang (Y). Definisi operasional variabel yang dibuat secara spesifik sesuai dengan kriteria pengujian berkaitan dengan variabel marketing mix, niat beli ulang dan kepuasan konsumen.

Data primer penelitian ini berupada kuisioner yang disebarkan kepada konsumen yang telah menggunakan produk Dewata Kaos minimal 2 kali. Data sekunder dalam penelitian ini diperoleh dari referensi pada buku, jurnal, internet dan lain sebagainya. Populasi yang digunakan adalah seluruh konsumen Dewata Kaos yang sudah pernah membeli produk Dewata Kaos yang tidak diketahui jumlah pastinya (Infinite). Sampel dari penelitian ini adalah beberapa konsumen Dewata Kaos di Kota Denpasar yang telah membeli produk Dewata Kaos minimal 2 kali. Penelitian ini dianalisis dengan multivariate dalam melakukan analisis maka jumlah 
anggota sampel disarankan minimal 5-10 kali dari jumlah indikator yang diteliti (Sugiyono, 2014:129). Jumlah indikator yang digunakan adalah 18 sehingga jumlah sampel yang diperlukan adalah 18 × $6=108$ hingga 110 responden.

Tabel 1.

Indikator Variabel Penelitian

\begin{tabular}{|c|c|c|c|c|}
\hline Variabel & Dimensi & & Indikator & Sumber \\
\hline & $\begin{array}{l}\text { Kualitas } \\
\text { Produk }\end{array}$ & $\begin{array}{l}\text { 1) } \\
\text { 2) } \\
\text { 3) }\end{array}$ & $\begin{array}{l}\text { Nilai Produk. } \\
\text { Kemasan Produk. } \\
\text { Ketahanan Produk. }\end{array}$ & $\begin{array}{l}\text { (Singh, 2012); } \\
\text { (Oktavia el al, 2013); } \\
\text { (Gronholm, 2012) }\end{array}$ \\
\hline \multirow{3}{*}{ Marketing Mix } & $\begin{array}{l}\text { Persepsi } \\
\text { Harga }\end{array}$ & $\begin{array}{l}\text { 1) } \\
\text { 2) } \\
\text { 3) }\end{array}$ & $\begin{array}{l}\text { Harga yang sesuai kualtas. } \\
\text { Harga yang terjangkau. } \\
\text { Harga bersaing dengan } \\
\text { produk lain. }\end{array}$ & $\begin{array}{l}\text { (Gronholm, 2012); } \\
\text { (Nugraheni \& } \\
\text { Ferdinan, 2013). }\end{array}$ \\
\hline & $\begin{array}{l}\text { Saluran } \\
\text { Distribusi }\end{array}$ & $\begin{array}{l}\text { 1) } \\
\text { 2) } \\
\text { 3) }\end{array}$ & $\begin{array}{l}\text { Kemudahan dalam } \\
\text { memperoleh produk. } \\
\text { Ketersediaan produk. } \\
\text { Lokasi pemberian produk. }\end{array}$ & $\begin{array}{l}\text { (Prastiwi, 2012); } \\
\text { (Gronholm, 2012). }\end{array}$ \\
\hline & $\begin{array}{c}\text { Daya Tarik } \\
\text { Promosi }\end{array}$ & $\begin{array}{l}\text { 1) } \\
\text { 2) } \\
\text { 3) }\end{array}$ & $\begin{array}{l}\text { Iklan yang menarik. } \\
\text { Ketepatan media promosi. } \\
\text { Pesan dalam iklam mudah } \\
\text { dimengerti. }\end{array}$ & $\begin{array}{l}\text { (Išoraite, 2016); } \\
\text { (Prastiwi, 2012). }\end{array}$ \\
\hline Niat Beli Ulang & & $\begin{array}{l}\text { 1) } \\
\text { 2) } \\
\text { 3) }\end{array}$ & $\begin{array}{l}\text { Melakukan pembelian } \\
\text { kembali. } \\
\text { Niat membeli kembali dengan } \\
\text { penambahan intensitas. } \\
\text { Tetap membeli kembali meski } \\
\text { harga naik. }\end{array}$ & $\begin{array}{l}\text { (Prastiwi, 2012), } \\
\text { (Chou \& Hsu, 2019) } \\
\text { dan (Yaqian, 2011). }\end{array}$ \\
\hline $\begin{array}{l}\text { Kepuasan } \\
\text { Konsumen }\end{array}$ & & $\begin{array}{l}\text { 1) } \\
\text { 2) } \\
\text { 3) }\end{array}$ & $\begin{array}{l}\text { Respon mengenai harapan. } \\
\text { Tanggapan yang berkaitan } \\
\text { dengan tindakan. } \\
\text { Pelayanan } \text { After service. }\end{array}$ & $\begin{array}{l}\text { ( Menaka et al., } \\
\text { 2017), ( Sanjaya et al, } \\
\text { 2016) dan } \\
\text { (Chairunnisa et al, } \\
\text { 2019) }\end{array}$ \\
\hline
\end{tabular}

Sumber: data diolah, 2020

Metode penetuan sample dengan purposive sampling yaitu teknik penentuan sampel dengan pertimbangan tertentu dengan menggunakan kuisioner. Jumlah sampel yang akan dijadikan responden sebanyak 110 orang. Kuesioner tersebut diukur dengan menggunakan skala Likert dengan perhitungan nilai skala 1 sampai dengan 5. Jenjang pendidikan minimal SMA/SMK sederajat dengan rentang usia mulai dari 17 tahun. Metode pengumpulan data dalam penelitian ini yaitu data primer yang didapat dengan menyebar kuisioner. Kuisioner disebar secara offline (secara langsung) dan online (google form) kepada responden yaitu konsumen 
dewata kaos yang berdomisili di kota Denpasar.

Teknik analisis data yang digunakan yaitu Uji asumsi klasik, Path Analysis dan Uji Sobel. Uji asumsi klasik yaitu dimana suatu model secara teoritis akan menghasilkan nilai parameter penduga yang tepat bila memenuhi persyaratan asumsi klasik regresi, yaitu meliputi uji normailitas, multikolineritas, dan heteroskedastisitas. Analisis jalur (path analysis) adalah perluasan dari analisis regresi linear berganda untuk menguji hubungan kausalitas antara dua atau lebih variabel. Perhitungan koefisien path analysis dilakukan dengan analisis regresi melalui software SPSS 18.0 for Windows.Uji Sobel digunakan dengan menguji kekuatan pengaruh tidak langsung variabel bauran pemasaran $(\mathrm{X})$ terhadap variabel niat beli ulang $(\mathrm{Y})$ melalui variabel kepuasan konsumen $(\mathrm{M})$.

\section{HASIL DAN PEMBAHASAN}

Data karakteristik responden berdasarkan pada variabel demografi yang terdiri dari jenis kelamin, usia, pendidikan terakhir dan pekerjaan yaitu:

Tabel 2.

Karakteristik Responden

\begin{tabular}{|c|c|c|c|c|}
\hline No & Variabel & Klasifikasi & $\begin{array}{l}\text { Jumlah } \\
\text { (Orang) }\end{array}$ & Presentase \\
\hline \multirow[t]{3}{*}{1} & Jenis Kelamin & Pria & 42 & $38,2 \%$ \\
\hline & & Wanita & 68 & 61,9 \\
\hline & Jumlah & & 110 & 100 \\
\hline \multirow[t]{5}{*}{2} & Usia & $16-26$ Tahun & 101 & $91,8 \%$ \\
\hline & & $27-37$ tahun & 1 & $9 \%$ \\
\hline & & $38-48$ tahun & 5 & $4,5 \%$ \\
\hline & & $49-59$ tahun & 3 & $2,7 \%$ \\
\hline & Jumlah & & 101 & 100 \\
\hline \multirow[t]{6}{*}{3} & Pekerjaan saat ini & $\begin{array}{l}\text { Pelajar / } \\
\text { Mahasiswa }\end{array}$ & 90 & $81,8 \%$ \\
\hline & & Pegawai Swasta & 9 & $8,2 \%$ \\
\hline & & Wiraswasta & 7 & $6,4 \%$ \\
\hline & & PNS & 3 & $2,7 \%$ \\
\hline & & Lain - lain & 1 & $0,9 \%$ \\
\hline & Jumlah & & 110 & 100 \\
\hline \multirow[t]{5}{*}{4} & Tingkat Pendidikan terakhir & SMA & 81 & $73,6 \%$ \\
\hline & atau yang sedang anda tempuh & D1/D2/D3 & 5 & $4,5 \%$ \\
\hline & & $\mathrm{S} 1$ & 22 & $20 \%$ \\
\hline & & $\mathrm{S} 2$ & 2 & $1,8 \%$ \\
\hline & Jumlah & & 110 & 100 \\
\hline
\end{tabular}

Sumber: data diolah, 2020

Berdasarkan data karakteristik responden yang ada pada tabel 2 terlihat bahwa, pada klasifikasi jenis kelamin cenderung di dominasi oleh responden wanita sebnayak 68 orang bila dibandingkan dengan responden berjenis kelamin pria sebanyak 42 orang.

Selanjutnya, dilihat dari klasifikasi usia responden mayoritas responden berusia $17-27$ tahun sebanyak 101 orang, diikuti kelompok usia $28-38$ tahun yaitu 1 orang, kemudian diikuti kelompok usia 39 - 49 tahun sebanyak 5 orang, 
terakhir kelompok usia $50-60$ tahun yaitu sebanyak 3 orang. Klasifikasi usia, di dominasi oleh kelompok usia 17 - 27 tahun, sebagai responden Dewata Kaos, karena usia tersebut cenderung usia produktif dan konsumtif dalam menggunakan pakaian sehingga mampu mengikuti trend fashion.

Klasifikasi pekerjaan pada kelompok di dominasi oleh mahasiswa sebanyak 90 orang, selanjutnya pegawai yaitu 9 orang, diikuti kelompok pekerjaan wiraswasta sebanyak 7 orang, selanjutnya PNS yaitu 3 orang dan kelompok terakhir yaitu pekerjaan lain - lain yaitu 1 orang.

Terakhir dengan klasifikasi tingkat Pendidikan, pada kelompok SMA sebanyak 81 orang, di ikuti kelompok Pendidikan diploma yaitu 5 orang, selanjutnya kelompok Pendidikan S1 sebanyak 22 orang dan terskhir kelompok Pendidikan S2 yaitu sebanyak 2 orang.

Variabel marketing mix dalam penelitian ini menggunakan 4 dimensi dengan 12 pernyataan untuk mengetahui jawaban responden yang ada di Kota Denpasar mengenai marketing mix yang di terapkan Dewata Kaos sehingga konsumen merasa puas dan berniat membeli ulang produk Dewata Kaos.

Tabel 3.

Deskripsi Jawaban Responden terhadap Marketing Mix

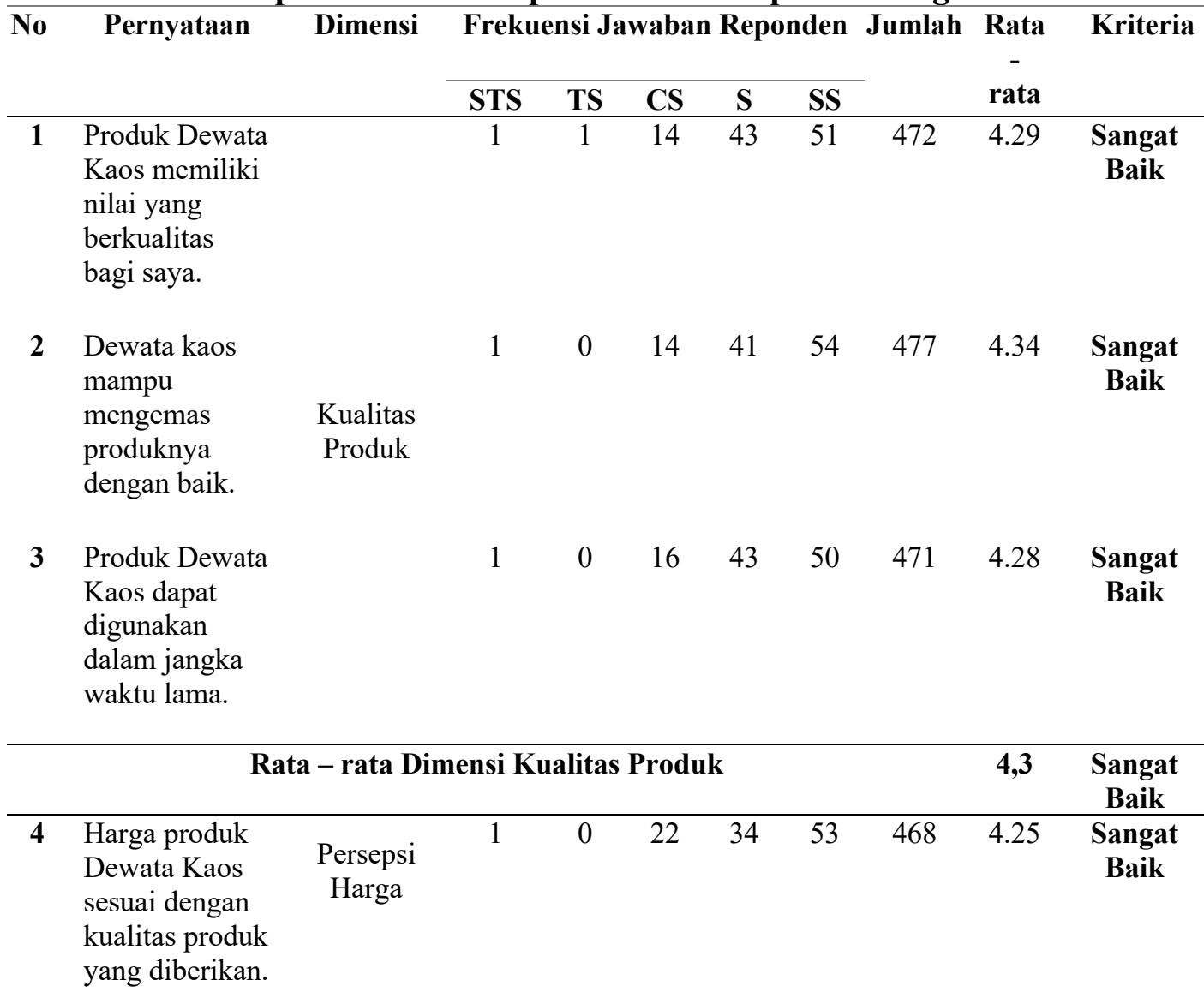

Bersambung... 
Lanjutan Tabel 3.

\begin{tabular}{|c|c|c|c|c|c|c|c|c|c|c|}
\hline \multirow[t]{2}{*}{ No } & \multirow[t]{2}{*}{ Pernyataan } & \multirow[t]{2}{*}{ Dimensi } & \multicolumn{4}{|c|}{ Frekuensi Jawaban Reponden } & \multicolumn{2}{|l|}{ Jumlah } & & \multirow[t]{2}{*}{ Kriteria } \\
\hline & & & STS & TS & $\mathrm{CS}$ & SS & & & & \\
\hline 5 & $\begin{array}{l}\text { Harga produk } \\
\text { Dewata Kaos } \\
\text { sesuai dengan } \\
\text { budget saya. }\end{array}$ & & 1 & 0 & 17 & 37 & 55 & 475 & 4.32 & $\begin{array}{c}\text { Sangat } \\
\text { Baik }\end{array}$ \\
\hline 6 & $\begin{array}{l}\text { Dewata kaos } \\
\text { menawarkan } \\
\text { harga produk } \\
\text { yang terjangkau, } \\
\text { dibandingkan } \\
\text { konfeksi } \\
\text { lainnya. }\end{array}$ & & 1 & 0 & 21 & 42 & 46 & 462 & 4.20 & Baik \\
\hline
\end{tabular}

\begin{tabular}{|c|c|c|c|c|c|c|c|c|c|c|}
\hline \multicolumn{9}{|c|}{ Rata - rata Dimensi Kualitas Persepsi Harga } & \multirow{2}{*}{$\begin{array}{l}\mathbf{4 , 2 5} \\
4.17\end{array}$} & \multirow{2}{*}{$\begin{array}{c}\begin{array}{c}\text { Sangat } \\
\text { Baik }\end{array} \\
\text { Baik }\end{array}$} \\
\hline 7 & $\begin{array}{l}\text { Produk Dewata } \\
\text { Kaos mudah di } \\
\text { peroleh } \\
\text { dipasaran }\end{array}$ & $\begin{array}{c}\text { Saluran } \\
\text { Distribusi }\end{array}$ & 2 & 2 & 20 & 37 & 49 & 459 & & \\
\hline 8 & $\begin{array}{l}\text { Ketersediaan } \\
\text { Produk Dewata } \\
\text { Kaos bervariasi }\end{array}$ & & 1 & 0 & 22 & 32 & 55 & 470 & 4.27 & $\begin{array}{c}\text { Sangat } \\
\text { Baik }\end{array}$ \\
\hline 9 & $\begin{array}{l}\text { Lokasi } \\
\text { pembelian } \\
\text { Produk Dewata } \\
\text { kaos mudah } \\
\text { diakses. }\end{array}$ & & 1 & 0 & 18 & 43 & 48 & 467 & 4.25 & $\begin{array}{c}\text { Sangat } \\
\text { Baik }\end{array}$ \\
\hline \multicolumn{9}{|c|}{ Rata - rata Dimensi Saluran Distribusi } & 4,23 & $\begin{array}{c}\text { Sangat } \\
\text { Baik }\end{array}$ \\
\hline 10 & $\begin{array}{l}\text { Dewata kaos } \\
\text { mampu } \\
\text { melakukan } \\
\text { promosi yang } \\
\text { menarik minat } \\
\text { saya. }\end{array}$ & & 1 & 0 & 26 & 46 & 37 & 448 & 4.07 & Baik \\
\hline 11 & $\begin{array}{l}\text { Media promosi } \\
\text { yang digunakan } \\
\text { Dewata Kaos } \\
\text { sudah tepat. }\end{array}$ & $\begin{array}{c}\text { Daya Tarik } \\
\text { Promosi }\end{array}$ & 1 & 0 & 21 & 41 & 47 & 463 & 4.21 & $\begin{array}{c}\text { Sangat } \\
\text { Baik }\end{array}$ \\
\hline 12 & $\begin{array}{l}\text { Dewata Kaos } \\
\text { menyampaikan } \\
\text { pesan promosi } \\
\text { yang dapat } \\
\text { dimengerti. }\end{array}$ & & 2 & 0 & 20 & 39 & 49 & 463 & 4.21 & $\begin{array}{c}\text { Sangat } \\
\text { Baik }\end{array}$ \\
\hline \multicolumn{9}{|c|}{ Rata - rata dimensi daya tarik promosi } & 4,16 & Baik \\
\hline \multicolumn{9}{|c|}{ Rata - rata keseluruhan marketing mix } & 4.24 & $\begin{array}{c}\text { Sangat } \\
\text { Baik }\end{array}$ \\
\hline
\end{tabular}

Perhitungan terkait hasil penelitian menunjukan bahwa nilai rata - rata 
keseluruhan jawaban responden mengenai strategi marketing mix Dewata Kaos bagi konsumen di Kota Denpasar ialah sebesar 4,24 dan dengan begitu dapat dikatakan masuk ke dalam kriteria sangat baik. Rata - rata tersebut menunjukan, bahwa strategi marketing mix yang sangat baik telah diterapkan oleh Dewata kaos dalam manajemen bisnisnya. Variabel niat beli ulang dinilai dari pernyataan pada tabel 3 sebagai berikut:

Tabel 4.

Deskripsi Jawaban Responden terhadap Niat Beli Ulang

\begin{tabular}{|c|c|c|c|c|c|c|c|c|c|}
\hline \multirow{2}{*}{ No } & \multirow{2}{*}{ Pernyataan } & \multicolumn{5}{|c|}{ Frekuensi Jawaban Responden } & \multirow{2}{*}{ Jumlah } & \multirow{2}{*}{$\begin{array}{l}\text { Rata } \\
\text { - rata }\end{array}$} & \multirow{2}{*}{ Kriteria } \\
\hline & & STS & TS & $\mathbf{C S}$ & $\mathbf{S}$ & SS & & & \\
\hline 1 & $\begin{array}{l}\text { Saya berniat } \\
\text { membeli kembali } \\
\text { Produk Dewata } \\
\text { Kaos. }\end{array}$ & 2 & 1 & 17 & 49 & 41 & 456 & 4.15 & Baik \\
\hline 2 & $\begin{array}{l}\text { Saya akan } \\
\text { memberitahu } \\
\text { keluarga beserta } \\
\text { kerabat tentang } \\
\text { Produk Dewata } \\
\text { kaos yang } \\
\text { berkualitas. }\end{array}$ & 2 & 0 & 18 & 39 & 51 & 467 & 4.25 & $\begin{array}{c}\text { Sangat } \\
\text { Baik }\end{array}$ \\
\hline 3 & $\begin{array}{l}\text { Saya tetap ingin } \\
\text { membeli produk } \\
\text { Dewata Kaos } \\
\text { meski harga yang } \\
\text { ditawarkan naik } \\
\text { dari harga } \\
\text { sebelumnya. }\end{array}$ & 3 & 4 & 32 & 38 & 33 & 424 & 3.85 & Baik \\
\hline \multicolumn{8}{|c|}{ Rata - rata keseluruhan Niat Beli Ulang } & 4.08 & Baik \\
\hline
\end{tabular}

Pada Tabel tersebut menunjukan bahwa nilai rata - rata keseluruhan jawaban mengenai niat beli ulang konsumen Dewata Kaos di Dewata Kaos adalah sebesar 4,08. Rata - rata jawaban dengan tersebut termasuk dapat dikatakan kriteria baik. Hal tersebut menunjukan niat beli ulang konsumen Dewata Kaos di Kota Denpasar memiliki nilai yang positif. Variabel kepuasan konsumen dalam penelitian ini menggunakan 3 pernyataan untuk mengetahui jawaban responden di Kota Denpasar mengenai kepuasan konsumen Dewata Kaos. Deskripsi jawaban secara rinci perhitungan hasil penelitian dapat dilihat pada Tabel 5 .

Hasil penelitian pada tabel 5 menunjukan, rata - rata keseluruhan pernyataan pada variabel kepuasan konsumen sebesar 4,19 dan dengan begitu dapat dikatakan dalam kriteria baik. Hal tersebut menunjukan konsumen di Kota Denpasar merasa puas terhadap produk Dewata Kaos.

Apabila koefesien korelasi $\geq 0,30$ maka instrumen tersebut dapat dikatakan valid, dengan tingkat kesalahan Alpha 0,05. Hasil uji validitas instrument penelitian akan disajikan pada Tabel 6 . 
Tabel 5.

Deskripsi Jawaban Responden terhadap Kepuasan Konsumen

\begin{tabular}{|c|c|c|c|c|c|c|c|c|c|}
\hline \multirow[t]{2}{*}{ No } & \multirow[t]{2}{*}{ Pernyataan } & \multicolumn{5}{|c|}{ Frekuensi Jawaban Reponden } & \multirow{2}{*}{ Jumlah } & \multirow{2}{*}{$\begin{array}{l}\text { Rata } \\
\text { - rata }\end{array}$} & \multirow{2}{*}{ Kriteria } \\
\hline & & STS & TS & $\mathbf{C S}$ & $\mathbf{S}$ & SS & & & \\
\hline 1 & $\begin{array}{l}\text { Saya merasa puas } \\
\text { dengan produk } \\
\text { Dewata kaos, } \\
\text { karena sesuai } \\
\text { dengan pesanan. }\end{array}$ & 2 & 0 & 17 & 43 & 48 & 465 & 4.23 & $\begin{array}{c}\text { Sangat } \\
\text { Baik }\end{array}$ \\
\hline 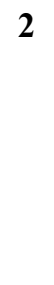 & $\begin{array}{l}\text { Saya akan } \\
\text { menjadi } \\
\text { pelanggan produk } \\
\text { Dewata Kaos } \\
\text { karena puas } \\
\text { dengan produk } \\
\text { yang dihasilkan. }\end{array}$ & 2 & 0 & 26 & 35 & 47 & 455 & 4.14 & Baik \\
\hline 3 & $\begin{array}{l}\text { Saya puas akan } \\
\text { pelayanan after } \\
\text { service berupa } \\
\text { perbaikan produk, } \\
\text { jika terjadi } \\
\text { masalah atau } \\
\text { kesalahan pada } \\
\text { produk Dewata } \\
\text { Kaos. }\end{array}$ & 2 & 0 & 22 & 36 & 50 & 462 & 4.20 & Baik \\
\hline & Rata - rats & reselu & K & uasa & Kon & nen & & 4.19 & Baik \\
\hline
\end{tabular}

Sumber: Data diolah, 2020

Tabel 6.

Hasil Uji Validitas

\begin{tabular}{ccccc}
\hline Variabel & Indikator & $\begin{array}{c}\text { Koefisien } \\
\text { Korelasi }\end{array}$ & Sig. (2tailed) & Keterangan \\
\hline \multirow{2}{*}{ X1.1 } & 0,870 & 0,000 & Valid \\
& $\mathrm{X} 1.2$ & 0,881 & 0,000 & Valid \\
$\mathrm{X} 1.3$ & 0,877 & 0,000 & Valid \\
$\mathrm{X} 2.1$ & 0,916 & 0,000 & Valid \\
$\mathrm{X} 2.2$ & 0,876 & 0,000 & Valid \\
Bauran & $\mathrm{X} 2.3$ & 0,862 & 0,000 & Valid \\
pemasaran (X) & $\mathrm{X} 3.1$ & 0,738 & 0,000 & Valid \\
& $\mathrm{X} 3.2$ & 0,803 & 0,000 & Valid \\
& $\mathrm{X} 3.3$ & 0,880 & 0,000 & Valid \\
& $\mathrm{X} 4.1$ & 0,889 & 0,000 & Valid \\
& $\mathrm{X} 4.2$ & 0,880 & 0,000 & Valid \\
& $\mathrm{X} 4.3$ & 0,861 & 0,000 & Valid \\
Kepuasan & $\mathrm{M}_{1}$ & 0,944 & 0,000 & Valid \\
konsumen & $\mathrm{M}_{2}$ & 0,960 & 0,000 & Valid \\
\cline { 2 - 4 } (M) & $\mathrm{M}_{3}$ & $\mathbf{0 , 9 5 0}$ & $\mathbf{0 , 0 0 0}$ & Valid
\end{tabular}

Bersambung... 
Lanjutan Tabel 6.

\begin{tabular}{ccccc}
\hline Variabel & Indikator & $\begin{array}{c}\text { Koefisien } \\
\text { Korelasi }\end{array}$ & Sig. (2tailed) & Keterangan \\
\hline Niat beli ulang (Y) & $\mathrm{Y}_{1}$ & 0,931 & 0,000 & Valid \\
& $\mathrm{Y}_{2}$ & 0,912 & 0,000 & Valid \\
& $\mathrm{Y}_{3}$ & $\mathbf{0 , 9 1 1}$ & $\mathbf{0 , 0 0 0}$ & Valid \\
\cline { 2 - 5 }
\end{tabular}

Sumber: data diolah, 2020

Hal tersebut menunjukkan bahwa seluruh variabel memiliki nilai koefisien korelasi dengan skor total seluruh item pernyataan lebih besar dari 0,30 dan menunjukkan bahwa butir-butir pernyataan dalam instrument penelitian valid.

Nilai Alpha Cronbach dinyatakan reliabel jika nilainya lebih besar atau sama dengan 0,60 . dapat dilihat pada Tabel 7. berikut :

Tabel 7.

Hasil Uji Reliabilitas

\begin{tabular}{cccc}
\hline No. & Variabel & $\begin{array}{c}\text { Cronbach's } \\
\text { Alpha }\end{array}$ & Keterangan \\
\hline $\mathbf{1}$ & Bauran pemasaran $(\mathrm{X})$ & 0,968 & Reliabel \\
$\mathbf{2}$ & Kepuasan konsumen $(\mathrm{M})$ & 0,947 & Reliabel \\
$\mathbf{3}$ & Niat beli ulang $(\mathrm{Y})$ & 0,903 & Reliabel \\
\hline \multicolumn{2}{l}{ Sumber: Data diolah,2020 }
\end{tabular}

Seluruh instrumen penelitian memiliki koefisien Cronbach's Alpha lebih dari 0,60. Hal ini dapat dikatakan bahwa semua instrumen reliabel sehingga dapat digunakan untuk melakukan penelitian.

Uji asumsi klasik dilakukan dengan tujuan untuk memastikan hasil yang diperoleh memenuhi asumsi dasar di dalam analisis regresi. Hasil uji asumsi klasik yang dilakukan dalam penelitian ini adalah uji normalitas, uji multikoliniearitas, dan uji heteroskedastisitas. Uji normalitas digunakan untuk menguji apakah data yang digunakan normal atau tidak dapat dilakukan dengan menggunakan uji Kolmogorov Sminarnov. Apabila koefisien Asymp. Sig. (2-tailed) lebih besar dari 0,05 maka data tersebut dikatakan berdistribusi normal, disajikan terkait hasil uji normalitas, sebagai berikut :

Tabel 8.

Hasil Uji Normalitas

\begin{tabular}{ccc}
\hline & $\begin{array}{c}\text { Unstandardized Residual } \\
\text { Struktur 1 }\end{array}$ & $\begin{array}{c}\text { Unstandardized Residual } \\
\text { Struktur 2 }\end{array}$ \\
\hline $\mathbf{N}$ & 110 & 110 \\
Kolmogorov-Smirnov $\boldsymbol{Z}$ & 2,117 & 1,315 \\
Asymp.Sig.(2-tailed) & 0,257 & 0,063 \\
\hline Sumber: data diolah, 2020 & &
\end{tabular}

Nilai Kolmogorov Sminarnov (K-S) pada struktur 1 sebesar 2,117, dengan nilai Asymp. Sig. (2-tailed) sebesar 0,257. Hasil tersebut mengindikasikan bahwa model persamaan regresi struktur 1 tersebut berdistribusi normal karena nilai Asymp. Sig. (2-tailed) lebih besar dari nilai alpha 0,05. Pada struktur 2 sebesar 
1,315, dengan nilai Asymp. Sig. (2-tailed) sebesar 0,063. Hasil tersebut mengindikasikan bahwa model persamaan regresi struktur 2 tersebut berdistribusi normal karena nilai Asymp. Sig. (2-tailed) lebih besar dari nilai alpha 0,05.

Uji multikolinearitas dapat dilihat dari nilai tolerance atau variance inflation factor (VIF). Jika nilai tolerance lebih dari 10\% atau VIF Kurang dari 10, maka dikatakan tidak ada multikolinearitas.

Tabel 9.

Hasil Uji Multikoleniaritas

\begin{tabular}{cccc}
\hline Persamaan Struktur & Variabel & Tolerance & VIF \\
\hline$=\mathbf{p 1 ~ X}+\mathbf{e}_{\mathbf{1}}$ & Bauran pemasaran (X) & 1,000 & 1,000 \\
$\mathbf{Y}=\mathbf{p} \mathbf{X} \mathbf{X}+\mathbf{p} \mathbf{3} \mathbf{M}+\mathbf{e}_{\mathbf{2}}$ & Bauran pemasaran (X) & 0,269 & 3,713 \\
& Kepuasan konsumen (M) & 0,269 & 3,713 \\
\hline
\end{tabular}

Sumber: data diolah, 2020

Nilai tolerance dan VIF dari variabel Bauran pemasaran, dan Kepuasan konsumen pada persamaan regresi struktur 1 dan 2 menunjukkan nilai tolerance untuk setiap variabel lebih besar dari $10 \%$ dan nilai VIF lebih kecil dari 10 yang berarti model persamaan regresi bebas dari multikolinearitas. Uji Heteroskedastisitas dinilai dari tingkat signifikansinya di atas 0,05 maka tidak mengandung gejala heteroskedastisitas, dimana memperoleh hasil sebagai berikut :

Tabel 10.

Hasil Uji Heteroskedastisitas Struktur 1

\begin{tabular}{|c|c|c|c|c|c|c|}
\hline & \multirow{2}{*}{ Model } & \multicolumn{2}{|c|}{$\begin{array}{c}\text { Unstandardized } \\
\text { Coefficients }\end{array}$} & \multirow{2}{*}{$\begin{array}{c}\begin{array}{c}\text { Standardized } \\
\text { Coefficients }\end{array} \\
\text { Beta }\end{array}$} & \multirow{2}{*}{$t$} & \multirow{2}{*}{ Sig. } \\
\hline & & $B$ & $\begin{array}{l}\text { Std. } \\
\text { Error }\end{array}$ & & & \\
\hline 1 & $\begin{array}{l}\text { (Constant) } \\
\text { Bauran pemasaran }\end{array}$ & $\begin{array}{l}0,061 \\
0,016\end{array}$ & $\begin{array}{l}0,558 \\
0,011\end{array}$ & 0,137 & $\begin{array}{l}0,109 \\
1,439\end{array}$ & $\begin{array}{l}0,913 \\
0,153\end{array}$ \\
\hline
\end{tabular}

Sumber: data diolah, 2020

Nilai signifikansi dari variabel Bauran pemasaran sebesar 0,153. Nilai tersebut lebih besar dari 0,05 yang berarti tidak terdapat pengaruh antara variabel bebas terhadap absolute residual, maka model yang dibuat tidak mengandung gejala heteroskedastisitas.

Tabel 11.

Hasil Uji Heteroskedastisitas Struktur 2

\begin{tabular}{|c|c|c|c|c|c|c|}
\hline \multirow{2}{*}{\multicolumn{2}{|c|}{ Model }} & \multicolumn{2}{|c|}{$\begin{array}{c}\text { Unstandardized } \\
\text { Coefficients }\end{array}$} & \multirow{2}{*}{$\begin{array}{c}\text { Standardized } \\
\text { Coefficients } \\
\text { Beta }\end{array}$} & \multirow{2}{*}{$t$} & \multirow{2}{*}{ Sig. } \\
\hline & & B & $\begin{array}{l}\text { Std. } \\
\text { Error }\end{array}$ & & & \\
\hline \multirow[t]{3}{*}{1} & (Constant) & 0,544 & 0,453 & & 1,202 & 0,232 \\
\hline & $\begin{array}{l}\text { Bauran } \\
\text { pemasaran }\end{array}$ & $-0,001$ & 0,017 & $-0,006$ & $0,030^{-}$ & 0,976 \\
\hline & $\begin{array}{l}\text { Kepuasan } \\
\text { konsumen }\end{array}$ & 0,021 & 0,057 & 0,068 & 0,364 & 0,717 \\
\hline
\end{tabular}

Sumber: data diolah,2020 
Nilai signifikansi dari variabel Bauran pemasaran sebesar 0,976 dan nilai signifikansi dari variabel Kepuasan konsumen sebesar 0,717. Nilai tersebut lebih besar dari 0,05 yang berarti tidak terdapat pengaruh antara variabel bebas terhadap absolute residual, maka model yang dibuat tidak mengandung gejala heteroskedastisitas.

Teknik analisis jalur (Path Analysis), dalm perhitungan koefisien path dilakukan dengan analisis regresi melalui software SPSS 18.0 for Windows, dengan hasil sebagai berikut :

Tabel 12.

Hasil Analisis Jalur Substruktur 1

\begin{tabular}{|c|c|c|c|c|c|}
\hline \multirow{2}{*}{ Variabel } & \multicolumn{2}{|c|}{$\begin{array}{l}\text { Unstandardized } \\
\text { Coefficients }\end{array}$} & \multirow{2}{*}{$\begin{array}{c}\begin{array}{c}\text { Standardized } \\
\text { Coefficients }\end{array} \\
\text { Beta }\end{array}$} & \multirow{2}{*}{$\mathbf{t}$} & \multirow{2}{*}{ Sig. } \\
\hline & B & Std. Error & & & \\
\hline (Constant) & $-0,307$ & 0,762 & & $-0,403$ & 0,688 \\
\hline Bauran pemasaran $(\mathrm{X})$ & 0,253 & 0,015 & 0,855 & 17,119 & 0,000 \\
\hline R Square & 0,731 & & & & \\
\hline Adjusted R Square & 0,728 & & & & \\
\hline F Statistik & 293,055 & & & & \\
\hline Signifikansi Uji F & 0,000 & & & & \\
\hline
\end{tabular}

Berdasarkan hasil analisis jalur substruktur 1 seperti yang disajikan, maka dapat dibuat persamaan struktural sebagai berikut :

$$
\mathrm{M}=0,253 \mathrm{X}+\mathrm{e}_{1}
$$

Nilai koefisien regresi variabel Bauran pemasaran bernilai positif dengan nilai signifikansi uji t kurang dari 0,05. Hal ini menunjukkan bahwa variabel Bauran pemasaran memiliki pengaruh positif yang signifikan terhadap variabel Kepuasan konsumen. Besarnya pengaruh variabel bebas terhadap variabel terikat yang ditunjukkan oleh nilai determinasi total (R Square) sebesar 0,731 mempunyai arti bahwa sebesar 73,1\% variasi Kepuasan konsumen dipengaruhi oleh variasi Bauran pemasaran, sedangkan sisanya sebesar $26,9 \%$ dijelaskan oleh faktor lain yang tidak dimasukkan ke dalam model.

\section{Tabel 13.}

Hasil Analisis Jalur Substruktur 2

\begin{tabular}{lccccc}
\hline \multicolumn{1}{c}{ Variabel } & \multicolumn{2}{c}{$\begin{array}{c}\text { Unstandardized } \\
\text { Coefficients }\end{array}$} & $\begin{array}{c}\text { Standardized } \\
\text { Coefficients }\end{array}$ & t & Sig. \\
\hline & B & $\begin{array}{c}\text { Std. } \\
\text { Error }\end{array}$ & Beta & & \\
(Constant) & 0,101 & 0,648 & & 0,156 & 0,876 \\
Bauran pemasaran (X) & 0,084 & 0,024 & 0,288 & 3,466 & 0,001 \\
Kepuasan konsumen (M) & 0,627 & 0,082 & 0,637 & 7,674 & 0,000 \\
R Square & 0,802 & & & & \\
Adjusted R Square & 0,798 & & & & \\
F Statistik & 216,114 & & & & \\
Signifikansi Uji F & 0,000 & & & &
\end{tabular}

Sumber: data diolah, 2020 
Hasil analisis jalur substruktur 2 seperti yang disajikan pada Tabel 12, maka dapat dibuat persamaan struktural sebagai berikut:

$$
\mathrm{Y}=0,084 \mathrm{X}+0,627 \mathrm{M}+\mathrm{e}_{2}
$$

Nilai signifikansi masing-masing variabel bebas kurang dari 0,050. Hal ini menunjukkan bahwa semua variabel bebas memiliki pengaruh yang signifikan terhadap variabel terikat. Besarnya pengaruh variabel bebas terhadap variabel terikat yang ditunjukkan oleh nilai determinasi total ( $\mathrm{R}$ Square) sebesar 0,802 mempunyai arti bahwa sebesar $80,2 \%$ variasi niat beli ulang dipengaruhi oleh variasi bauran pemasaran dan kepuasan konsumen, sedangkan sisanya sebesar 19,8\% dijelaskan oleh faktor lain yang tidak dimasukkan ke dalam model.

Menguji nilai koefisien determinasi $\left(\mathrm{R}^{2}\right)$ dan variabel error (e). Berdasarkan model substruktur 1 dan substruktur 2, maka dapat disusun model diagram jalur akhir. Sebelum menyusun model diagram jalur akhir, terlebih dahulu dihitung nilai standar error :

$$
\begin{aligned}
& \mathrm{Pe}_{\mathrm{i}}=\sqrt{1-\mathrm{R}_{\mathrm{i}}{ }^{2}} \ldots \ldots \ldots \ldots \ldots \ldots \ldots(1) \\
& \mathrm{Pe}_{1}=\sqrt{1-R_{1}{ }^{2}}=\sqrt{1-0,731}=0,518 \\
& \mathrm{Pe}_{2}=\sqrt{1-{R_{2}}^{2}}=\sqrt{1-0,802}=0,445
\end{aligned}
$$

Berdasarkan perhitungan pengaruh error (Pei), didapatkan hasil pengaruh error $\left(\mathrm{Pe}_{1}\right)$ sebesar 0,518 dan pengaruh error $\left(\mathrm{Pe}_{2}\right)$ sebesar 0,445. Hasil koefisien determinasi total adalah sebagai berikut :

$$
\begin{aligned}
\mathrm{R}^{2} \mathrm{~m} & =1-\left(\mathrm{Pe}_{1}\right)^{2}\left(\mathrm{Pe}_{2}\right)^{2} \\
& =1-(0,731)^{2}(0,802)^{2} \\
& =1-(0,518)(0,445) \\
& =1-0,2305=0,7695
\end{aligned}
$$

Nilai determinasi total sebesar 0,7695 mempunyai arti bahwa sebesar 76,95\% variasi niat beli ulang konsumen dipengaruhi oleh variasi bauran pemasaran dan kepuasan konsumen, sedangkan sisanya sebesar $76,95 \%$ djelaskan oleh faktor lain yang tidak dimasukkan ke dalam model.

Perhitungan Koefisien Jalur Secara Parsial. Menjelaskan interpretasi

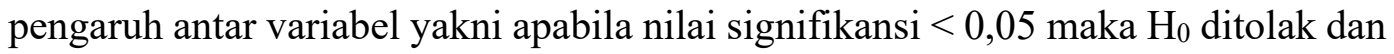
$\mathrm{H}_{1}$ diterima. Sebaliknya, jika nilai signifikansi $>0,05$ maka $\mathrm{H}_{0}$ diterima dan $\mathrm{H}_{1}$ ditolak. Berati Marketing mix berpengaruh positif dan signifikan terhadap niat beli ulang. Hasil analisis pengaruh Bauran pemasaran terhadap Kepuasan konsumen diperoleh nilai signifikansi sebesar 0,000 dengan nilai koefisien regresi positif sebesar 0,253 dengan nilai t hitung sebesar 17,119. Nilai Signifikansi 0,000<0,05 mengindikasikan bahwa $\mathrm{H}_{0}$ ditolak dan $\mathrm{H}_{1}$ diterima.

Hasil ini mempunyai arti bahwa bauran pemasaran berpengaruh positif dan signifikan terhadap kepuasan konsumen. Analisis data pengaruh Bauran pemasaran terhadap Niat beli ulang diperoleh hasil dimana nilai signifikansi sebesar 0,001 
dengan nilai koefisien regresi positif sebesar 0,084 dan nilai t hitung sebesar 3,466. Nilai Signifikansi 0,001 $<0,05$ mengindikasikan bahwa $\mathrm{H}_{0}$ ditolak dan $\mathrm{H}_{2}$ diterima. Hasil ini mempunyai arti bahwa bauran pemasaran berpengaruh positif dan signifikan terhadap niat beli ulang konsumenHasil analisis pengaruh Kepuasan konsumen terhadap Niat beli ulang diperoleh nilai signifikansi sebesar 0,00 dengan nilai koefisien regresi positif sebesar 0,627 dan nilai t hitung sebesar 7,674. Nilai Signifikansi $0,000<0,05$ mengindikasikan bahwa $\mathrm{H}_{0}$ ditolak dan $\mathrm{H}_{3}$ diterima. Hasil ini mempunyai arti bahwa kepuasan konsumen berpengaruh positif dan signifikan terhadap niat beli ulang konsumen. Hasil koefisien jalur pada hipotesis penelitian dapat digambarkan, sebagai berikut:

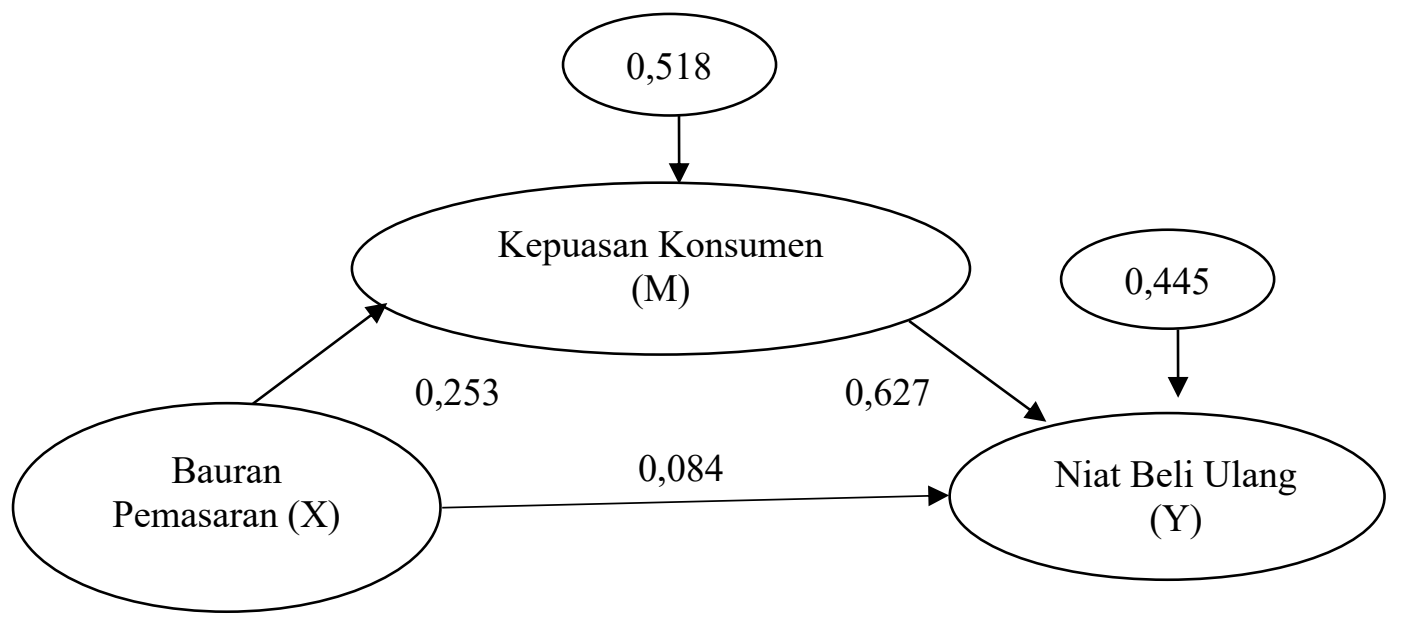

Gambar 2. Validasi Model Diagram Jalur Akhir

Sumber: data diolah, 2020

Gambaran diagram tersebut dapat menggambarkan besarnya pengaruh langsung dan pengaruh tidak langsung serta pengaruh total antar variabel, dirangkum sebagai berikut.

Tabel 14.

Pengaruh Langsung dan Pengaruh Tidak Langsung serta Pengaruh Total Variabel Penelitian

\begin{tabular}{cccc}
\hline $\begin{array}{c}\text { Pengaruh } \\
\text { Variabel }\end{array}$ & $\begin{array}{c}\text { Pengaruh } \\
\text { Langsung }\end{array}$ & $\begin{array}{c}\text { Pengaruh Tidak Langsung Melalui } \\
\text { Kepuasan konsumen } \\
(\mathbf{Y 1})(\boldsymbol{\beta 1} \mathbf{x} \boldsymbol{\beta 3})\end{array}$ & Pengaruh Total \\
\hline $\mathbf{X} \rightarrow \mathbf{M}$ & 0,253 & - & 0,253 \\
$\mathbf{X} \rightarrow \mathbf{Y}$ & 0,084 & 0,158 & 0,242 \\
$\mathbf{M} \rightarrow \mathbf{Y}$ & 0,627 & - & 0,627 \\
\hline
\end{tabular}

Sumber: Data diolah, 2020

Hasil pengaruh tidak langsung serta pengaruh total, pada Tabel diatas secara rinci dapat dilihat pada perhitungan berikut : 
Pengaruh tidak langsung :

$$
X \rightarrow M \rightarrow Y=\left(\beta_{1}\right) \times\left(\beta_{3}\right)=0,253 \times 0,627=0,158
$$

Pengaruh Total :

$$
\begin{aligned}
& =\beta_{2}+\left(\beta_{1} \times \beta_{3}\right) \ldots \ldots \ldots \ldots(3) \\
& =0,084+(0,253 \times 0,627)=0,242
\end{aligned}
$$

Perhitungan diatas menunjukkan bahwa pengaruh langsung bauran pemasaran terhadap kepuasan konsumen adalah sebesar 0,253. Pengaruh langsung variabel bauran pemasaran terhadap niat beli ulang sebesar 0,084. Pengaruh langsung variabel kepuasan konsumen terhadap niat beli ulang sebesar 0,627. Hal ini berarti bahwa variabel niat beli ulang lebih besar dipengaruhi oleh kepuasan konsumen dibandingkan bauran pemasaran. Sedangkan pengaruh tidak langsung variabel bauran pemasaran terhadap niat beli ulang melalui kepuasan konsumen sebesar 0,158 . Jadi pengaruh total variabel bauran pemasaran terhadap niat beli ulang melalui kepuasan konsumen adalah sebesar 0,242.

Uji sobel merupakan alat analisis untuk menguji signifikansi dari hubungan tidak langsung antara variabel independen dengan variabel dependen yang dimediasi oleh variabel mediator. Bila nilai kalkulasi $\mathrm{Z}$ lebih besar dari 1,96 (dengan tingkat kepercayaan 95 persen), maka variabel mediator dinilai secara signifikan memediasi hubungan antara variabel terikat dan variabel bebas. Pengujian pengaruh tidak langsung variabel Bauran pemasaran (X) terhadap variabel Niat beli ulang (Y) melalui variabel kepuasan konsumen (M). Rumusan Hipotesis, dimana $\mathrm{H}_{0}$ Kepuasan Konsumen tidak mampu memediasi variabel Bauran Pemasaran terhadap Kepuasan Konsumen $\mathrm{H}_{1}$ Kepuasan Konsumen mampu memediasi variabel Bauran Pemasaran terhadap Kepuasan Konsumen

Kriteria pengujian yang digunakan adalah, jika $\mathrm{Z}$ hitung $\leq 1,96$ maka $\mathrm{H}_{0}$ diterima, berarti kepuasan konsumen bukan variabel mediasi. Jika $Z$ hitung $>$ 1,96 maka $\mathrm{H}_{0}$ ditolak, berarti kepuasan konsumen merupakan variabel mediasi.

Menghitung Statistik Uji untuk menguji signifikansi pengaruh tidak langsung maka nilai $\mathrm{z}$ dari koefisien ab dihitung dengan rumus sebagai berikut :

$$
\begin{aligned}
& S_{b 1 b 3}=\sqrt{(0,627)^{2}(0,015)^{2}+(0,253)^{2}(0,082)^{2}+(0,015)^{2}(0,082)^{2}} \\
& S_{b 1 b 3}=0,022811
\end{aligned}
$$

Menguji signifikansi pengaruh tidak langsung maka menghitung nilai z dari koefisien ab dengan rumus sebagai berikut:

$$
\begin{aligned}
& Z=\frac{b 1 b 3}{S b 1 b 3} \ldots \ldots \ldots \ldots \ldots .(4) \\
& Z=\frac{(0,253)(0,627)}{0,022811} \\
& Z=6,954 \ldots \ldots \ldots \ldots \ldots \ldots \ldots \ldots \ldots \ldots(8)
\end{aligned}
$$


Hasil uji sobel dalam penelitian ini menunjukan $\mathrm{Z}$ hitung sebesar 6,954> 1,96. Dengan tingkat signifikansi $0,000<0,05$ yang artinya kepuasan konsumen (M) merupakan variabel yang memediasi bauran pemasaran (X) terhadap niat beli ulang (Y) atau dengan kata lain bauran pemasaran berpengaruh secara tidak langsung terhadap niat beli ulang melalui kepuasan konsumen.

Strategi marketing mix sebagai strategi dasar diharapkan mampu secara konsisten diterapkan untuk meningkatkan dan mendorong niat beli ulang konsumen Dewata Kaos. Konsumen merasa puas terhadap strategi marketing mix yang diterapkan, sehingga konsumen menjadi berlangganan yang otomatis mendorong niat pembelian ulang hingga rekomendasi konsumen kepada orang terdekat untuk memesan di Dewata Kaos.Implikasi teoritis yang berkaitan dengan niat beli ini dapat memperkuat teori sebelumnya pada variabel kepuasan konsumen terhadap suatu produk dan strategi Marketing Mix yang diterapkan untuk mecapai hal tersebut. Implikasi praktis, dari hasil penelitian ini dapat digunakan sebagai masukan dan evaluasi khususnya bagi perusahaan Dewata Kaos dan perusahaan manufaktur lainnya pada umumnya.

Ruang Lingkup serta sampel penelitian, dari penelitian ini yang sangat terbatas hanya berlaku pada Produk Dewata Kaos, menyebabkan hasil penelitian tidak dapat di generalisasikan.Jumlah responden dalam penelitian terbatas, karena tidak semua masyarakat di Kota Denpasar sebagai konsumen Dewata Kaos yang telah menggunakan produk Dewata kaos minimal sebanayak dua kali. Hal tersebut mengakibatkan peneliti harus menyebar kuisioner dengan menelusuri data konsumen Dewata Kaos di Kota Denpasar. Menyebarkan kuisioner penelitian secara online dan offline untuk memenuhi kriteria jumlah sample yang dibutuhkan dalam penelitian ini,

\section{SIMPULAN}

Berdasarkan hasil uji sobel dalam penelitian ini menunjukan $\mathrm{Z}$ hitung sebesar $6,954>1,96$. Dengan tingkat signifikansi $0,000<0,05$ yang artinya kepuasan konsumen $(\mathrm{M})$ merupakan variabel yang memediasi marketing mix (X) terhadap niat beli ulang (Y) atau dengan kata lain (74\%) bauran pemasaran berpengaruh secara tidak langsung terhadap niat beli ulang melalui kepuasan konsumen. Artinya bahwa, semakin baik penerapan Marketing Mix maka konsumen akan lebih berniat membali kembali prosuk Dewata Kaos di Kota Denpasar. Marketing Mix berpengaruh positif dan signifikan terhadap kepuasan konsumen. Artinya bahwa, semakin baik penerapan strategi Marketing Mix maka pelanggan akan merasa semakin puas terhadap produk Dewata Kaos di Kota Denpasar. Kepuasan pelanggan berpengaruh positif dan signifikan terhadap niat beli ulang yang Artinya bahwa, semakin tinggi tingkat kepuasan pelanggan maka akan semakin kuat pengaruhnya terhadap niat beli ulang konsumen Dewata Kaos di Kota Denpasar. Hasil keseluruhan maka, Kepuasan konsumen mampu memediasi pengaruh marketing mix terhadap niat beli ulang pada produk Dewata Kaos di Denpasar. Artinya bahwa, semakin baik penerapan strategi marketing mix pada perusahaan akan semakin kuat pengaruhnya terhadap niat beli ulang konsumen Dewata Kaos dikota Denpasar dengan kepuasan konsumen sebagai variabel yang memediasi. 
Pihak Dewata Kaos perlu melakukan pengembangan strategi bauran pemasaran atau marketing mix yang berorientasi kepada strategi marketing mix dimana pada dimensi daya tarik promosi, melakukan promosi yang lebih menarik minat konsumen. Promosi yang lebih menarik, sehingga konsumen lebih tertarik terhadap promosi yang disampaikan. Promosi pada social media marketing, platform online dan website disarankan sekaligus mengikuti perkembangan marketing pada era digital melalui Facebook ads, Instagram ads dengan konten yang kreatif serta inovatif. Dewata Kaos perlu memperhatikan khususnya terhadap produk yang dihasilkan agar lebih berkualitas. Menerima kritikan dan saran konsumen terhadap kekurangan produk sebagai evaluasi, sehingga dapat meningkatkan perfoma produk. Lebih memperhatikan perbaikan pada strategi marketing mix yang diterapkan sehingga berdampak pada kepuasan konsumen yang dirasakan. Saran yang dapat diberikan, dengan meningkatkan promosi melalui discount, membuat kartu member dewata kaos serta konsisten terhadap kualitas produk dan layanan. Terkait penelitian selanjutnya, diharapakan mampu menambah variabel penelitian yang mempengaruhi niat beli ulang, serta mampu memperluas ruang lingkup penelitian yang tidak hanya terbatas pada produk Dewata Kaos atau dapat juga mengganti lokasi penelitian. Hal ini perlu dilakukan, agar dapat memberikan suatu pandangan yang lebih dan mampu diimplementasikan secara umum.

\section{REFERENSI}

Chayana, P. R., Manajemen, P. M., Pascasarjana, F., \& Parahyangan, U. K. (2014). Pengaruh Bauran Pemasaran Jasa "House of Baloon” terhadapa minat Beli Ulang.13(2),131-150.

Chou, S. W., \& Hsu, C. S. (2019). Understanding online repurchase intention: social exchange theory and shopping habit. Information Systems and EBusinessManagement,14(1),19-45.

Dimyati, M., \& Mohamad Dimyati, Ms. (2018). Media acana $W$ P e $n$ e r $b$ it The Hayati Approach: a Marketing Strategy The Hayati Approach: a Marketing Strategy For Dynamic Competition For Dynamic Competition The Hayati Approach:a Marketing Strategy For Dynamic Competition.

Farida, I., Tarmizi, A., \& November, Y. (2016). Analisis Pengaruh Bauran Pemasaran 7P Terhadap Kepuasan Pelanggan Pengguna Gojek Online. Jurnal Riset Manajemen Dan Bisnis (JRMB) Fakultas Ekonomi UNIAT, 1(1), 31-40.

Ferrand, A., Robinson, L., \& Valette-Florence, P. (2010). The intention-torepurchase paradox: A case of the health and fitness industry. Journal of Sport Management,24(1),83-105.

Gronholm. (2012). Marketing concepts in practice, case study: Company X. International Business Bachelor' sthesis. Lahti University. 
Išoraitè, M. (2016). Marketing Mix Theoretical Aspects. International Journal of Research-Granthaalayah,4(6),25-37.

Kadhim, D. F. A., Abdullah, T. F., \& Abdullah, M. F. (2016). Effects Of Marketing Mix On customer Satisfaction: Empirical Study On Tourism industry In Malaysia. International Journal of Applied Research, 2(2), 4.

Kusuma, P., \& Suryani, A. (2017). Peran Customer Satisfaction Memediasi Pengaruh Marketing Mix Terhadap Repurchase Intention. E-Jurnal Manajemen Universitas Udayana, 6(3), 254993.

Menaka, P., \& Thangadurai, K. (2017). Customer Satisfaction in Scrm With Key Performance Indicator System. ICTACT Journal on Management Studies, 03(02), 515-522.

Nathadewi, K. S., \& Sukawati, T. G. R. (2019). Peran Kepuasan Dalam Memediasi Pengaruh Kualitas Pelayanan Terhadap Niat Beli Ulang Konsumen Lion Air. E-Jurnal Manajemen Universitas Udayana, 8(11), 6658.

Nugraheni, Rini dan Comaeni Enril Ferdinan. 2013. Analisis Pengaruh Persepsi Harga, Persepsi Kualitas Produk dan Promosi Terhadap Keputusan Pembellian Sepeda Motor Suzuki (Studi Pada Pembeli - Penguna Sepeda Motor Suzuki di Kota Solo). Diponegoro Journal of Management, 2(2), hal. $1-8$.

Oktavia Riska, suharyono dan Kadarisman Hidayat. 2013. Pengaruh bauran pemasaran terhadap keputusan pembelian (survai pada mahasiswa yang mengkonsumsi teh botol sosro jurusan ilmu administrasi bisnis angkatan 2012/2013 fakultas ilmu administrasi universitas brawijaya malang). Jurnal administrasi bisnis, 3(2), pp: 1-8.

Othman, B., Harun, A., Sadq, Z. M., \& Rashid, W. N. (2020). Effects of Service Marketing Mix on Umrah Customer Satisfaction : Empirical Study on Umrah Traveling Industry in Malaysia. The Mattingley Publishing, 4(95).

Palma, M. A., \& Andjarwati, A. L. (2016). Pengaruh Kualitas Produk, Kemudahan, Dan Harga Terhadap Niat Beli Ulang Dengan Kepuasan Sebagai Variabel Intervening (Studi Pada Pelanggan Produk Fashion Melalui Toko online di Surabaya). Jurnal Riset Ekonomi Dan Manajemen, 16(1), 84.

Prastiwi. Septi Kurnia. 2012. Analisis anteseden loyalitas dan wom serta pengaruh nya terhadap Repurchase Intention pada produk susu sgm (studi pada orang tua siswa teman sejati sari husada Yogyakarta). Riset manajemen \& akuntansi, 3(6), pp: 57-88. . 
Resti, Devi; Soesanto, H. (2016). Pengaruh Persepsi Harga, Kualitas Pelayanan melalui Kepuasan Pelanggan terhadap Minat Beli Ulang pada Rumah Kecantikan Sifra Di Pati. Diponegoro Journal of Management, 5(1), 1-12.

Untung Sanjaya Dan Klemens Wedanaji Prasatyo (2016). Pengaruh Kualitas Layanan, Harg Dan Kepuasan Pelanggan Terhadap Loyalitas Penonton Untuk Menonton Film, Jurnal Bisnis Dan Akuntansi. Stie Trisakti. ISSN: 1410 - 9875

Singh, M. (2012). Marketing Mix of 4P'S for Competitive Advantage. IOSR Journal of Business and Management, 3(6), 40-45.

Siti Jahroh, S. S. C. I. F. (2019). How Important Is Green Marketing Mix For Consumer? Lesson From The Body Shop. Jurnal Manajemen, 23(2), 321.

Sugiyono. (2014). Metode Penelitian Manajemen. Bandung: Alfabeta.

Supriyanto, E. (2013). "Manufaktur” dalam Dunia Teknik Industri. Industri Elektro Dan Penerbangan, 3(3), 1-4.

Taali, M. (2018). Pengaruh bauran pemasaran ( marketing mix ) terhadap pengambilan eputusan menginap di The Sun Hotel Madiun. Jurnal Epicheirisi, 2(1), 13-21.

Tejantara, A., Gde, T., \& Sukawati, R. (2018). Pelanggan Untuk Meningkatkan Niat Pembelian Ulang ( Studi Pada Oli Sepada Motor Merek Eni di Kota Denpasar ). 7(10), 5686-5718.

Wahyudi, T., \& Prawatya, Y. E. (2012). Analisis Pengaruh Marketing Mix Terhadap Kepuasan Konsumen Sepeda Motor. Jurnal Riset Manajemen Dan Bisnis, 4(2), 34-38.

Yaqian, Z. (2011). The Impact of CostumerBased Brand Equity on Revisit Intentions: An Empirical Study of Five Sahanghai Budget Hotels. AUGSB EJournal (Online), 4(1). 